\section{The Day Atomic Resolution Microscopy Happened}

\author{
Allan J. Melmed \\ Custom Probes Unlimited \\ Alpine Research and Development Laboratory \\ Terra Alta, $W V$ \\ ajm3@gcnetmail.net
}

Microscopists only dreamed about seeing atoms until 1951. The concept of atoms is believed to have originated in the writings of Democritus in 430 B.C., actually seeing images of atoms in a microscope became a fact only in 1951 with the publication by Erwin W. Müller, announcing his field ion microscope, FIM(1). Typical of the great scientist that he was, Müller immediately thought of ways to improve his new microscope and his goal then became achieving atomic resolution microscopy as he thought of it - the ability to not only see individual atoms, but to resolve the adjacent atoms comprising the atomic lattice of a crystal surface. No other microscope achieved this during Müller's lifetime (1911-1977)! This goal was pursued during the following four years, in Müller's new laboratory at Penn State and by his former Berlin students and colleagues.

In his landmark 1951 paper, Müller suggested that resolution could be improved by cooling the specimen (tip) and by replacing hydrogen with a heavier imaging gas such as helium. Imaging with a cooled tip in hydrogen was tried in 1953 in Berlin and with tip cooling and helium in 1954 at Penn State, but both experiments failed to achieve atomic resolution imaging. Thus, the logical approach of simply improving the resolution of the 1951 FIM, evidently was not the route to success. In view of the fact that the FIM actually did later achieve atomic resolution, this may now seem to be a paradox.

The solution to the apparent paradox became clear later and I have written about it in detail (2). FIM resolution was indeed improved by imaging with helium at low tip temperature - but ironically, because it was not known at the time, the big obstacle to success was not insufficient resolution, rather it was the thermal disorder of the surfaces being imaged! No matter how much the resolution was improved, the surface atomic lattice could not be seen because it was covered by a layer of thermally disorded atoms. Figure 1 shows a modern micrograph of a thermally disordered $\mathrm{W}$ surface, imaged at low temperature. This superficial disorder results from the heating used to clean the curved FIM specimen surface, and has to be removed in order to reveal for imaging the atomic perfection Müller wanted so dearly to see.

I joined Müller's Penn State laboratory in the autumn of 1954, working mostly with field electron microscopy (FEM), and became good friends with Kanwar Bahadur, a doctoral student who had joined the laboratory a year earlier to work with Müller on the FIM resolution problem. Over the next year, Bahadur realized that Mül- ler was becoming increasingly pessimistic of achieving his goal of atomic resolution microscopy, and when Bahadur suggested trying one more time to improve resolution by tip cooling Müller, knowing that two earlier experiments had failed, was not enthusiastic about repeating the cooling experiment. However, Bahadur persisted for "some reason", and built a special microscope tube to try the experiment one more time.

The historical fact is that on October 11, 1955, Bahadur repeated the cooling experiment and atomic resolution microscopy was observed! He called Prof. Müller into the lab to see the amazing result and upon leaving the laboratory some time later, Müller quietly said, "Atoms, ja atoms." Erwin Müller's goal was finally achieved and the scientific world was led to believe that the logical approach of cooling the FIM tip led directly to this great achievement. However, the actual explanation of why it happened that day occurred to me only 40 years later (2). It resulted from the seemingly mundane procedure of specimen preparation! Kanwar Bahadur's well-honed skill in making very sharp FIM specimens produced an extra-sharp tip, which was exactly what was needed to allow considerable field evaporation, despite the blunting effect of the heating cycles he used. And this is why atomic resolution microscopy happened on October 11, 1955. Figure 2 shows a helium field ion micrograph of a $\mathrm{W}$ tip after low-temperature field evaporation, imaged at low temperature.
It is fascinating to recognize how deeply entrenched in the FEM - FIM specimen preparation procedure the final step of high temperature heating had become. After all, Erwin Müller had made his great achievements in FEM by determining that heating the specimen to high temperature in ultra-high vacuum was the way to produce a clean surface. And with his leadership, everyone believed that the key to seeing the surface atomic lattice, by FIM, was to first remove all surface contamination by heating. So, heating became the standard procedure prior to imaging by FEM, and was naturally carried over to FIM.

If we fast-forward to a few years after October 11, 1955, we find that most FIM workers discarded the heat treating procedure. It simply became known that tip heating was not necessary, and caused tip blunting.

Much later, I became curious to see how good the room-temperature FIM is for resolving surface atomic structure. Recognizing

- 
that FIM resolution improves somewhat with decreasing tip radius, and that in the first years of FIM very small tips were not practical to image, due to the reduced image intensity, it seemed interesting to try room-temperature FIM with very sharp tips, aided by a modern image intensifier. The result, published in 1995 (2), showed that for tips with radii less than about $10 \mathrm{~nm}$, atomic spacings of $0.3 \mathrm{~nm}$ could be resolved. Thus, the conjecture made by FIM researchers in the early 1950's that FIM then had atomic resolution capability was confirmed.

In closing, I want to emphasize that Erwin Müller's original FIM (1951) was a monumental achievement in the history of microscopy, the creation of an experimental genius, and inherently had the resolving power to image adjacent lattice atoms (2). However, in view of what I have described, it is logical to ask "What credit should Kanwar Bahadur get?" There is no doubt in my mind that if Kanwar Bahadur had not worked with Erwin Müller when he did, atomic resolution microscopy would certainly not have occurred in 1955 at PSU, and there is no way to suggest where and when atomic resolution microscopy would then have happened. Bahadur caused the October 11, 1955 event to happen. I believe that it is fair to say that FIM was invented by Erwin Müller in 1951, and that Kanwar Bahadur was the first person to image an atomically resolved surface lattice.

\section{References}

1. E. W. Müller, Z. Physik 131 (1951) 136.

2. A. J. Melmed, Appl. Surf. Sci. 94/95 (1996) 17.

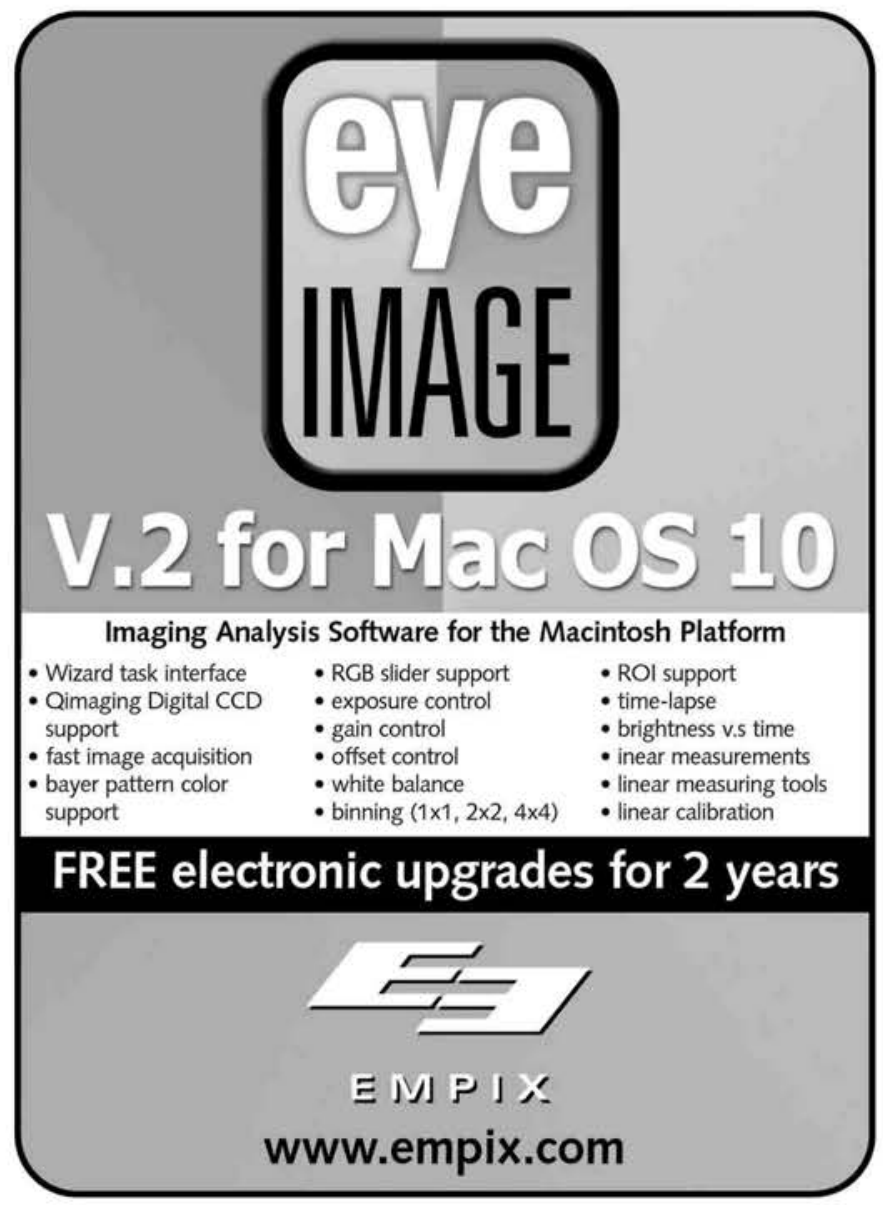

\section{The Problem: Black Square Deposits}

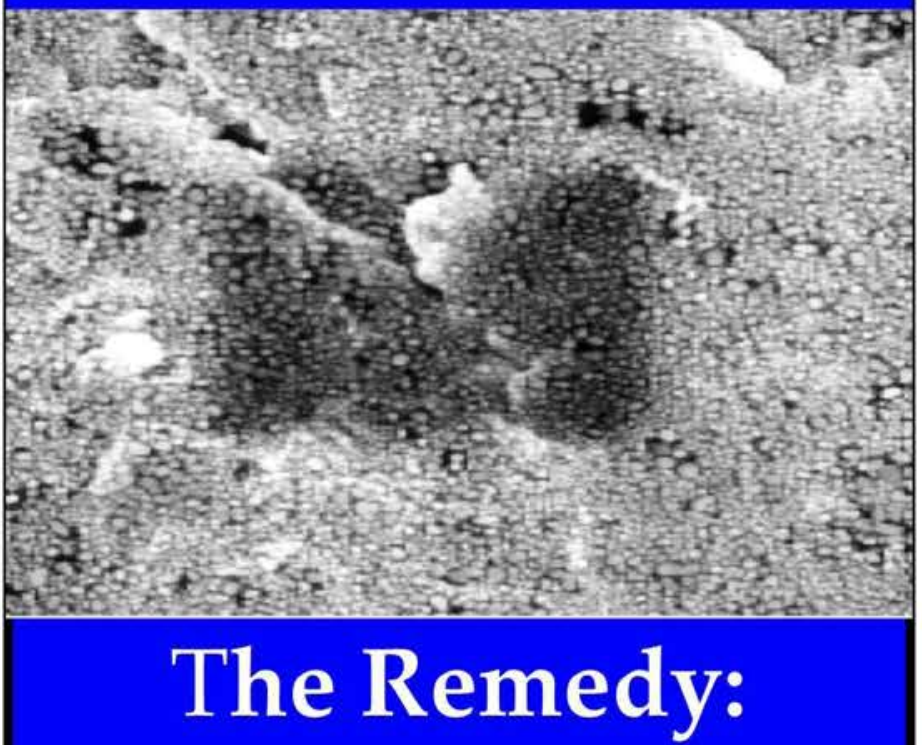

Evactron $^{\circledR}$
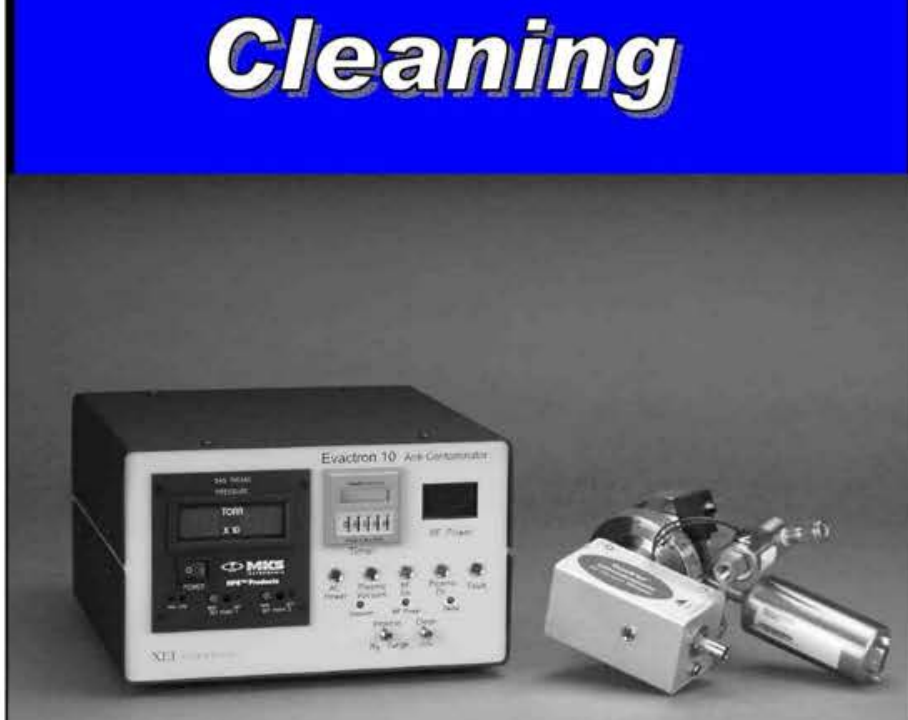

The Evactron ${ }^{\circledR}$ De-Contaminator with Oxygen Radical Source (ORS) mounts on your SEM or FIB.

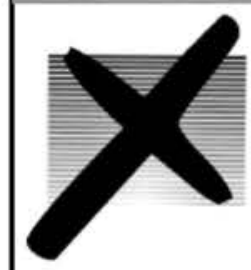

XEI scientific, INC. 1735 East Bayshore Rd, Suite 29A Redwood City, CA 94063 (650) 369-0133, FAX (650) 363-1659 email:sales@Evactron.com WWw.EVACTRON.COM 